\title{
Antifungal activity of dihydrobenzofuran neolignans
}

\begin{abstract}
In this study, we report on the antifungal activity in vitro of eight dihydrobenzofuran neolignans (DBNs) against selected dermatophytes in terms of their minimal inhibitory concentrations (MIC). Our results revealed that compound $3(( \pm)$-trans-dehydrodicafeate dimethyl ester $), 4(( \pm)$-4-O-acetyl-trans-dehydrodicoumarate dimethyl ester) and 7 $\left(( \pm)-7^{\prime}, 8^{\prime}\right.$-dihydro-7,8-dehydro-trans-dehydrodicoumarate dimethyl ester) were weakly active $(\mathrm{MIC}=1000 \mu \mathrm{g} / \mathrm{mL})$ against Trichophyton mentagrophytes, whereas the other DBNs were inactive $(\mathrm{MIC}>1000 \mu \mathrm{g} / \mathrm{mL})$. These data, as compared with previous reports in the literature, suggest that a methyl ester function at C9 and C9' decrease the antifungal activity of DBN.
\end{abstract}

Keywords: dihydrobenzofuran neolignans, trichophyton mentagrophytes, dermatophytes
Volume 6 Issue 4 - 2017

\author{
Herbert J Dias,' 'Nayara A S Aquaroni, ${ }^{2}$ \\ Rosimeire C L R Pietro, ${ }^{2}$ Antônio E M \\ Crotti $^{3}$ \\ 'Department of Chemistry, University of São Paulo, Brazil \\ ${ }^{2}$ Department of Drugs and Medicines, Universidade Estadual \\ Paulista (UNESP), Brazil
}

\section{Correspondence: Antônio EM Crotti, Departamento de Química, Faculdade de Filosofia, Ciências e Letras de Ribeirão Preto, Universidade de São Paulo, Av. Bandeirantes, 3900, Monte Alegre, CEP |4040-90| Ribeirão Preto, SP, Brazil, Tel +55 16 3515 3747, Fax 551635154838 , Email millercrotti@ffclrp.usp.br \\ Received: November 15, 2017 | Published: November 24, 2017}

Abbreviations: DBN, dihydrobenzofuran neolignans; DDQ, 2,3-dichloro-5,6-dicyano-p-benzoquinone; EI-MS, electron ionization mass spectrometry; IR, infrared spectroscopy; Pyr, pyridine; NMR, nuclear magnetic resonance

\section{Introduction}

Superficial fungal infections of the skin, hair, and nails are dermatomycoses that affect the individuals' health quality of life and are considered a public health issue. ${ }^{1-3}$ Dermatological infections affect more than $25 \%$ of the people worldwide living in tropical and subtropical regions, mainly individuals involved in outdoor activities, such as agriculture, lumbering, and hunting, among others. ${ }^{4-6}$ The responsible for the dermatomycoses is pointed out as dermatophytes, non-dermatophytic filamentous and yeasts forms of fungi, but in most of the cases, the etiologic agents are the dermatophytes. ${ }^{7}$ Furthermore, the species causative of dermatomycoses demonstrate considerable variation depending on the geographical location, economic situations as well as population migrations and weather conditions, and can affect the treatment of such fungal infections..$^{1,6,8}$

Besides the dermatomycoses have been increased over the years, the known treatment available for these diseases is still based on the use of triazoles (fluconazole, itraconazole, voriconazole), imidazoles (ketoconazole), allylamines (terbinafine) and griseofulvin. ${ }^{9}$ The resistance to these therapeutic agents, as well as the increasing number of immunocompromised individuals by HIV, transplanted individuals, and individuals in cancer treatment, have decreased the number of effective drugs available for the treatment of dermatomycoses. ${ }^{10}$ In this scenario, there has been an increasing interest for the search of lead compounds to be used in the treatment of dermatomycoses. ${ }^{11,12}$

Dihydrobenzofuran neolignans (DBN) are compounds derived from the coupling of two phenylpropanoids $\left(\mathrm{C}_{6} \mathrm{C}_{3}\right.$ units $)$ linked specifically by $7.0 .4^{\prime}$ and $8.5^{\prime}$ positions. ${ }^{13,14}$ Various biological activities have been reported for DBN, such as anti-inflammatory, ${ }^{15}$ antileishmanial, ${ }^{16}$ antitumor, ${ }^{17}$ antioxidant, and cytotoxic. ${ }^{18}$ DBNs have been also reported to display interesting antifungal activities. ${ }^{19-22}$ Thus, as part of our ongoing project on the biological activities of dihydrobenzofuran neolignans, in this paper we investigate the antifungal activity of eight synthetic DBN against selected dermatophytes.

\section{Materials and methods}

\section{Synthesis of dihydrobenzofuran neolignans I-8}

The dihydrobenzofuran neolignans $1 \quad(( \pm)$-transdehydrodicoumarate dimethyl ester), $2(( \pm)$-trans-dehydrodiferulate dimethyl ester) and $3(( \pm)$-trans-dehydrodicafeate dimethyl ester $)$ (Figure 1) were synthesized by oxidative coupling of methyl coumarate (a), ferulate (b) and caffeate (c), respectively, employing silver (I) oxide as oxidant agent, as previously described by Medeiros and co-workers. ${ }^{23}$ Further acetylation of 1 and 2 afforded $4(( \pm)-4-O$-acetyl-trans-dehydrodicoumarate dimethyl ester) and 5 $(( \pm)-4-O$-acetyl-trans-dehydrodiferulate dimethyl ester). Oxidation with DDQ and further hydrogenation produced $6(( \pm)$-7,8-dehydrotrans-dehydrodicoumarate dimethyl ester) and $7\left(( \pm)-7^{\prime}, 8^{\prime}\right.$-dihydro7,8-dehydro-trans-dehydrodicoumarate dimethyl ester), respectively. In addition, hydrogenation of compound 1 afforded compound 8 $\left(( \pm)-7^{\prime}, 8^{\prime}\right.$-dihydro-trans-dehydrodicoumarate dimethyl ester). These compounds were synthesized employing previously procedures reported with modifications. ${ }^{24-26}$ All the structures were confirmed on the basis of NMR, EI-MS and IR data and comparison with the literature. ${ }^{23,26}$

\section{Antifungal activity}

The antifungal activity of compounds 1-8 against Candida albicans (ATCC 64548), Candida parapsilosis (ATC 90028), Candida glabrata (ATCC 22019), Candida krusei (ATCC 90030), Candida tropicalis (ATCC 6258) and Trichophyton mentagrophytes (INCQS 40051) was evaluated in terms of minimum inhibitory concentration (MIC), according to the standard M38-A2 of the Clinical and Laboratory Standards Institute (CLSI) protocol with some modifications, as described below. ${ }^{27}$

Compounds 1-8 were dissolved in dimethylsulfoxide (DMSO) at $2 \mathrm{mg} / \mathrm{mL}$ (stock solution). The inoculum of the fungi strains 
were suspended in $0.9 \%$ saline solution and adjusted to obtain approximately $5 \times 103 \mathrm{CFU} / \mathrm{mL}$. Then, $100 \mu \mathrm{L}$ of the cell suspensions were applied in 96-wells cell culture microplates, added to compounds 1-8, $125 \mu \mathrm{L}$ DMSO and $1875 \mu \mathrm{L}$ of RPMI 1640 medium. Serial dilutions were performed by transferring $50 \mu \mathrm{L}$ from the previous well to the following. Compounds 1-8 were tested at final concentrations between 1000 and $6.25 \mu \mathrm{g} / \mathrm{mL}$. Tests and controls were performed in triplicate, using negative controls of sterility for RPMI
1640 medium and DMSO and a positive control of bacterial growth The microplates were incubated by adding $20 \mu \mathrm{L}$ of a $0.01 \%$ aqueous solution $(30 \mu \mathrm{L}, 0.01 \%)$ of resazurin. After incubation at $37^{\circ} \mathrm{C}$ for $1 \mathrm{~h}$, the minimum inhibitory concentration was determined as the lowest concentration of the sample capable of preventing the colour of the resazurin solution from changing. ${ }^{28}$ Amphotericin $\mathrm{B}$ was used as positive control at concentrations from 0.156 to $16,0 \mu \mathrm{g} / \mathrm{mL}$.

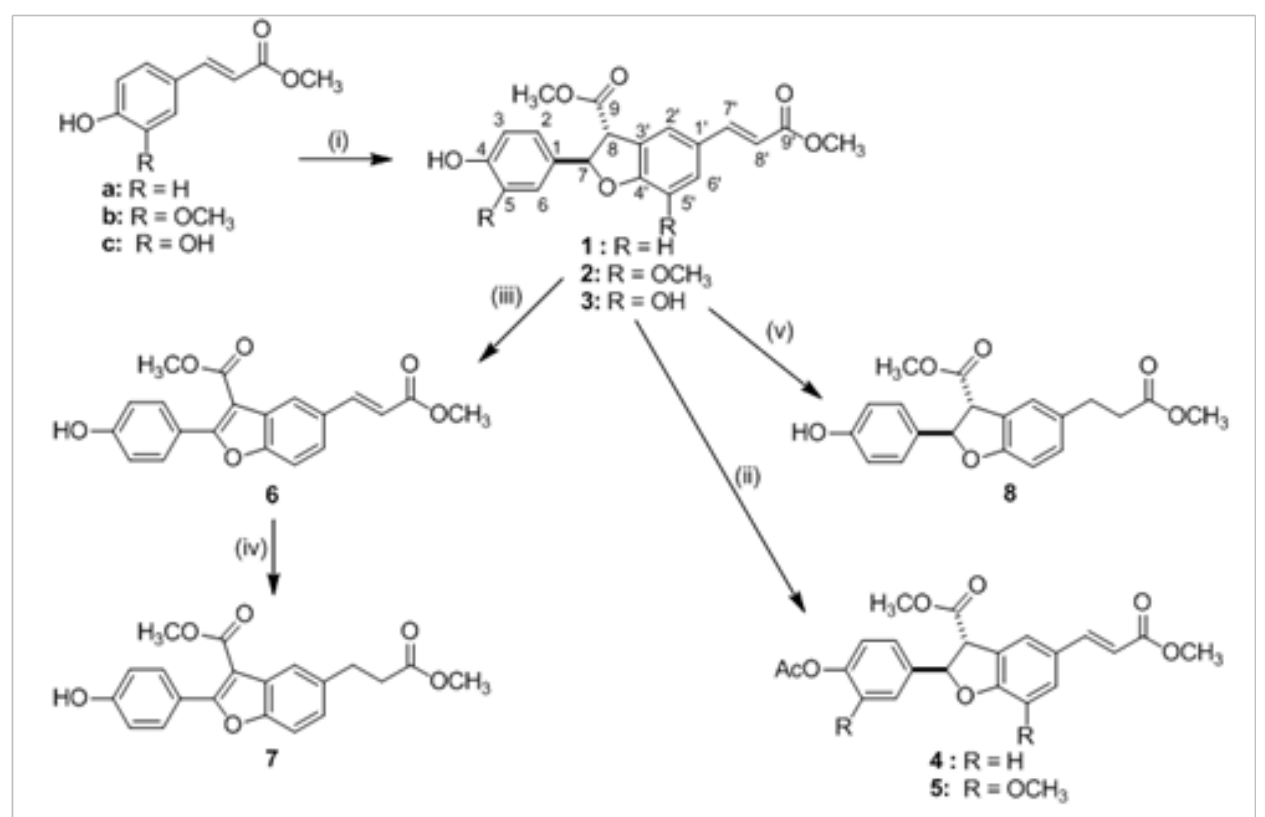

Figure I Synthesis of compounds I-8. (i) $\mathrm{Ag}_{2} \mathrm{O}, \mathrm{Me}_{2} \mathrm{CO} / \mathrm{C}_{6} \mathrm{H}_{6} 5: 8$ (v/v), r.t., $20 \mathrm{~h}$; yields=34\% for I, $40 \%$ for 2 ; and $36 \%$ for 3 ; (ii) $\mathrm{Ac}_{2} \mathrm{O}$, Pyr, $48 \mathrm{~h}$, r.t.; yields of $96 \%$ for 4 and $82 \%$ for 5; (iii) DDQ, dioxane, $105^{\circ} \mathrm{C}, 22 \mathrm{~h}$;Yield of $74 \%$ for 6 ; (iv) $\mathrm{h}_{2}, \mathrm{Pd} / \mathrm{C}$ (5\%), 60 psi, $2 \mathrm{~h}$;Yield of $96 \%$ for 7; (v) $\mathrm{h}_{2}, \mathrm{Pd} / \mathrm{C}, 60 \mathrm{psi}, 2 \mathrm{~h}$;Yields of $96 \%$ for 8 .

\section{Results and discussion}

We investigated the antifungal activity of compounds 1-8 against selected dermatophytes in terms of their minimum inhibitory concentration (MIC) values as compared to Amphotericin B (positive control). Table 1 summarizes the MIC values. The lowest MIC values were obtained for 3, 4 and $7(\mathrm{MIC}=1000 \mu \mathrm{g} / \mathrm{mL})$ against $T$. mentagrophytes.

Table I Minimum inhibitory concentration (MIC) values $(\mu \mathrm{g} / \mathrm{mL})$ of compounds I-8 against selected fungi

\begin{tabular}{lllllll}
\hline Compound & C.Parapsilosis & C.Albicans & C.Tropicalis & C. Krusei & C. Glabrata & T. Mentagrophytes \\
\hline 1 & $>1000$ & $>1000$ & $>1000$ & $>1000$ & $>1000$ & 1000 \\
2 & $>1000$ & $>1000$ & $>1000$ & $>1000$ & $>1000$ & $>1000$ \\
3 & $>1000$ & $>1000$ & $>1000$ & $>1000$ & $>1000$ & 1000 \\
4 & $>1000$ & $>1000$ & $>1000$ & $>1000$ & $>1000$ & $>1000$ \\
5 & $>1000$ & $>1000$ & $>1000$ & $>1000$ & $>1000$ & $>1000$ \\
6 & $>1000$ & $>1000$ & $>1000$ & $>1000$ & $>1000$ & $>1000$ \\
7 & $>1000$ & $>1000$ & $>1000$ & $>1000$ & $>1000$ & $>1000$ \\
PC & $>1000$ & 0.5 & 0.5 & 0.5 & 0.5 & 0.5
\end{tabular}

PC, positive control (Amphotericin B)

According to the literature, MIC values lower than $100 \mu \mathrm{g} / \mathrm{mL}$, between 500 and $1000 \mu \mathrm{g} / \mathrm{mL}$, and higher than $1000 \mu \mathrm{g} / \mathrm{mL}$ correspond to promising, moderate and weak activities, respectively, whereas MIC values higher than $1000 \mu \mathrm{g} / \mathrm{mL}$ denotes inactivity. ${ }^{21}$ Based on these criteria, compounds $\mathbf{3}, \mathbf{4}$ and $\mathbf{7}$ displayed weak activity against T. mentagrophytes, whereas all the other tested compounds were inactive against the other selected dermatophytes.
Pessini and co-workers reported the antifungal activity of conocarpan, O-methylconocarpan, epomatenoid-4, epomatenoid-5 and epomatenoid-6 isolated from Pipper regnelli against C. albicans, C.krusei, C. parapsilosis, C. tropicalis and T. mentagophytes. Conocarpan was the most active among these compounds, with MIC values of $6.25 \mu \mathrm{g} / \mathrm{mL}$ against $C$. albicans and $C$. tropicalis. Based on these results, the authors suggested that the presence of phenol hydroxyl 
group increase the antifungal activity, whereas the presence of double bond at furan ring (C7-C8) decreases the antifungal activity. In this study, we evaluated eight synthetic dihydrobenzofuran neolignans displaying different structure features from those natural compounds investigated by Pessini and co-workers. Our results, as compared with those previously reported, ${ }^{21}$ strongly suggested that the presence of a methyl ester function at $\mathrm{C} 9$ and $\mathrm{C} 9$ ' decreases the antifungal activity of DBNs. However, the fact that most of the compounds investigated were inactive against the selected dermatophytes in the range of tested concentration makes difficult to propose other structure-activity relationships.

\section{Conclusion}

The results obtained from this study demonstrated that compound 1-8 are inactive or weakly active against the selected dermatophytes. Considering that some structure-activity relationships could not be evidenced from these data, further studies on the antifungal activity of other dihydrobenzofuran neolignans displaying wider structure diversity should be undertaken.

\section{Acknowledgements}

The authors thank the Brazilian Foundation FAPESP (grant no. 2013/20094-0) for financial support and CNPq for fellowships.

\section{Conflict of interest}

The author declares no conflict of interest.

\section{References}

1. Havlickova B, Czaika VA, Friedrich M. Epidemiological trends in skin mycoses worldwide. Mycoses. 2008;51(Suppl 4):2-15.

2. Ameen M. Epidemiology of superficial fungal infections. Clin Dermatol. 2010;28(2):197-201

3. Guarner J. Human immunodeficiency virus and fungal infections. Semin Diagn Pathol. 2017;34(4):325-331.

4. Flemming A. Fungal infection: JNK inhibitors boost antifungal immunity Nature Rev Immunol. 2017;17(3):148-149.

5. Giacomazzi J, Baethgen L, Carneiro LC, et al. The burden of serious human fungal infections in Brazil. Mycoses. 2017;59(3):145-150.

6. Simmonet C, Berger F, Gantlier JC. Epidemiology of superficial fungal diseases in French Guiana: a three-year retrospective analysis. Med Mycol. 2011;46(6):608-611.

7. Silva LB, de Oliveira DBC, da Silva BV, et al. Identification and antifungal susceptibility of fungi isolated from dermatomycoses. $J$ Eur Acad Dermatol Venereol. 2014;28(5):633-640.

8. Koksal F, Er E, Samasti M. Causative agents of superficial mycoses in Istanbul, Turkey: retrospective study. Mycopathologia. 2009;168(3):117123

9. Meis JF, Verweij PE. Current management of fungal infections. Drugs. 2001;61(Suppl 1):13-25.

10. Zhao X, Guo Y, Jiang C, et al. JNK1 negatively controls antifungal innate immunity by suppressing CD23 expression. Nat Med. 2017;23(3):337346.

11. Gupta D, Jain D. Chalcone derivatives as potential antifungal agents: Synthesis, and antifungal activity. J Adv Pharm Technol Res. 2015;6(3):114-117.
12. Wang $\mathrm{H}$, Ren $\mathrm{S}-\mathrm{X}, \mathrm{He} \mathrm{Z}-\mathrm{Y}$, et al. Synthesis, antifungal activities and qualitative structure activity relationship of carabrone hydrazone derivatives as potential antifungal agents. Int J Mol Sci. 2014;15(3):42574272 .

13. Gottlieb OR. The rational search for natural neolignans. Mem Inst Oswaldo Cruz. 1991;86(Suppl II):25-29.

14. Moss GP. Nomenclature of lignans and neolignans. Pure Appl Chem 2000;72(8):1493-1523

15. Cho JY, Baik KU, Yoo ES, et al. In vitro anti inflammatory effects of neolignan woorenosides from the rhizomes of Coptis japonica. $J$ Nat Prod. 2000;63(9):1205-1209.

16. Miert SV, Dyck SV, Schmidt TJ, et al. Antileishmanial activity, cytotoxicity and QSAR analysis of synthetic dihydrobenzofuran lignans and related benzofurans. Bioorg Med Chem. 2005;13(3):661-669.

17. Pieters L, Van Dyck S, Gao M, et al. Synthesis and biological evaluation of dihydrobenzofuran lignans and related compounds as potential antitumor agents that inhibit tubulin polymerization. $J$ Med Chem. 1999;42(26):5475-5481.

18. Huang $\mathrm{X}-\mathrm{X}$, Zhou $\mathrm{C}-\mathrm{C}$, Li $\mathrm{L}-\mathrm{Z}$, et al. Cytotoxic and antioxidant dihydrobenzofuran neolignans from the seeds of Crataegus pinnatifida. Fitoterapia. 2013;91(91):217-223

19. Koroishi AM, Foss SR, Cortez DAG, et al. In vitro antifungal activity of extracts and neolignans from Piper regnellii against dermatophytes. $J$ Ethnopharmacol. 2008;117(2):270-277.

20. Apers S, Vlietinck A, Pieters L. Lignans and neolignans as lead compounds. Phytochem Rev. 2003;2(3):201-217.

21. Pessini GL, Dias Filho BP, Nakamura CV, et al. Antifungal activity of the extracts and neolignans from Piper regnellii (Miq.) C. DC. var pallescens (C. DC.) Yunck. J Braz Chem Soc. 2005;16(6):1130-1133.

22. Phatchana R, Thongsri Y, Somwaeng R, et al. Canangalias A and B from the stem bark of Cananga latifolia. Phytochem Lett. 2015;13(9):147-151.

23. Medeiros TCT, Dias HJ, Silva EO, et al. Detailed $1 \mathrm{H}$ and $13 \mathrm{C}$ NMR spectral data assignment of two dihydrobenzofuran neolignans. J Braz Chem Soc. 2016;27(1):136-143.

24. Kuo YH, Wu CH. Synthesis of 5-(3-Hydroxypropyl)-7-methoxy-2(3'-methoxy-4'-hydroxyphenyl)-3-benzo[b]furancarbaldehyde, a novel adenosine A1 receptor ligand from the root of Salvia miltiorrhiza J Nat Prod. 1996;59(6):625-628.

25. Maeda S, Masuda H, Tokoroyama T. Studies on the preparation of bioactive lignans by oxidative coupling reaction. III. Synthesis of polyphenolic benzofuran and coumestan derivatives by oxidative coupling reaction of methyl (E)-3-(4-hydroxy-2-methoxyphenyl) propenoate and their inhibitory effect on lipid peroxidation. Chem Pharm Bull. 1994;42(12):2536-2545.

26. Pieters L, Van Dyck S, Gao M, et al. Synthesis and biological evaluation of dihydrobenzofuran lignans and related compounds as potential antitumor agents that inhibit tubulin polymerization. $J$ Med Chem. 1999;42(26):5475-5481.

27. CLSI. National Committee for Clinical Laboratory Standards Reference Method for Broth Dilution Antifungal Susceptilibity Testing of Filamentous Fungi: Approved Standard M-38A2. Clinical and Laboratory Standards Institute; 2008. 28(16):35.

28. Sarker SD, Nahar L, Kumarasamy Y. Microtitre plate based antibacterial assay incorporating resazurin as an indicator of cell growth, and its application in the in vitro antibacterial screening of phytochemicals. Methods. 2007;42(4):321-324. 